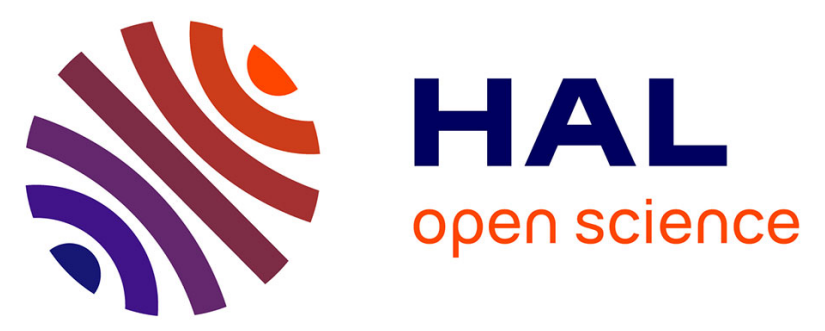

\title{
Customers' flexibility valued in market and regulated environment
}

Ricardo Mendes André, Gisela Mendes, Tuukka Rautiainen, Eduardo Jiménez, Carlos Varandas, Nuno Lopes, Andrea Michiorri, Guido Pires, Pedro Matos

\section{To cite this version:}

Ricardo Mendes André, Gisela Mendes, Tuukka Rautiainen, Eduardo Jiménez, Carlos Varandas, et al.. Customers' flexibility valued in market and regulated environment. CIRED 2016 workshop - Electrical networks for society and people , CIREC - Centre International de Recherche sur l'Environnement et le Développement, Jun 2016, Helsinki, Finland. hal-01398445

\section{HAL Id: hal-01398445 \\ https://hal-mines-paristech.archives-ouvertes.fr/hal-01398445}

Submitted on 17 Nov 2016

HAL is a multi-disciplinary open access archive for the deposit and dissemination of scientific research documents, whether they are published or not. The documents may come from teaching and research institutions in France or abroad, or from public or private research centers.
L'archive ouverte pluridisciplinaire HAL, est destinée au dépôt et à la diffusion de documents scientifiques de niveau recherche, publiés ou non, émanant des établissements d'enseignement et de recherche français ou étrangers, des laboratoires publics ou privés. 


\section{CUSTOMERS' FLEXIBILITY VALUED IN MARKET AND REGULATED ENVIRONMENT}

\author{
Ricardo MENDES ANDRÉ \\ EDP NEW R.\&.D - Portugal \\ ricardo.andre@edp.pt \\ Eduardo JIMÉNEZ \\ INDRA - Spain \\ ejsegado@indra.es \\ Andrea MICHIORRI \\ Armines - France \\ andrea.michiorri@mines-paristech.fr
}

\author{
Gisela MENDES \\ EDP NEW R.\&.D - Portugal \\ gisela.mendes@edp.pt \\ Carlos VARANDAS \\ EDP Labelec - Portugal \\ carlosalves.varandas@edp.pt \\ Guido PIRES \\ EDP Distribuição - Portugal \\ guido.pires@edp.pt
}

\author{
Tuukka RAUTIAINEN \\ Empower - Finland \\ tuukka.rautiainen@empower.fi \\ Nuno LOPES \\ EDP Labelec - Portugal \\ Nuno.lopesfilipe@edp.pt \\ Pedro MATOS \\ EDP Comercial - Portugal \\ pedro.matos@edp.pt
}

\section{ABSTRACT}

The upcoming smart grid paradigm brings a new approach for distribution grid management, regarding new technical features for DSO and new energy services to be provided to final customers. On the one hand these technical features and energy services become possible a more efficient management of distribution grid aiming at a reduction of grid investment and operational cost, not only in investment but also in operation and management. On the other hand these new services for clients may become possible an increase on energy efficiency and energy cost reduction for clients, with direct impact in environmental goals worldwide.

This paper describes a use case developed under SENSIBLE Project to be implemented in the Portuguese DemonstratorÉvora, where low voltage $(L V)$ clients provide flexibility through the usage of energy storage and energy management technologies, both in regulated and market environment, optimizing customers' energy consumption and minimizing its cost, and, simultaneously, providing grid services when grid technical constraints occur with indirect impact in grid investment costs.

\section{INTRODUCTION}

The increase of renewable generation in distribution grids combined with increasingly volatile load diagrams raises the necessity for a more flexible grid. This flexibility can be provided by the DSO in a Business as Usual (BaU), approach or by the grid users themselves, through innovative schemes. The SENSIBLE project - Storage-Enabled Sustainable Energy for Buildings and Communities is an $\mathrm{H} 2020$ funded project focused on energy storage and energy management technologies developments applied both for grid and end user applications, with three complementary demonstrators, Portugal-Évora, Germany-Nuremberg and United KingdomNottingham. The Portuguese demonstrator adopts a wide focus with several use cases focused in grid applications and end customers' energy services development. This paper describes a use case developed under SENSIBLE Project currently in development in the Portuguese demonstrator, where clients provide flexibility through the use of energy storage and energy management technologies, both in regulated and market environment, optimizing customers' energy consumption and minimizing its cost, providing at same time, grid services in case of grid technical constraints.

\section{PORTUGUESE FRAMEWORK}

Figure 1 outlines a general outlook about the energy cost structure in Portugal, where it can be seen that in LV grid about $40 \%$ of the cost is due energy cost, due to generation, retail and trading. Here are included the costs from the market in day-ahead and intraday timeframes, where some deviations from forecasts are corrected. Moreover about $60 \%$ of energy structure cost in LV is due to grid accesses, that includes distribution grid, transmission grid as well as other system costs. This leads to the conclusion that acting on grid access and energy price would have a considerable impact in energy cost to final LV client. Despite the good quality of service and the high level of reliability, the current grid infrastructure is ancient and needs to undergo significant adjustments to handle the future challenges, namely higher peak demand, greater control over energy costs, losses reduction and lower O\&M cost. Despite these upcoming challenges for the reliability of

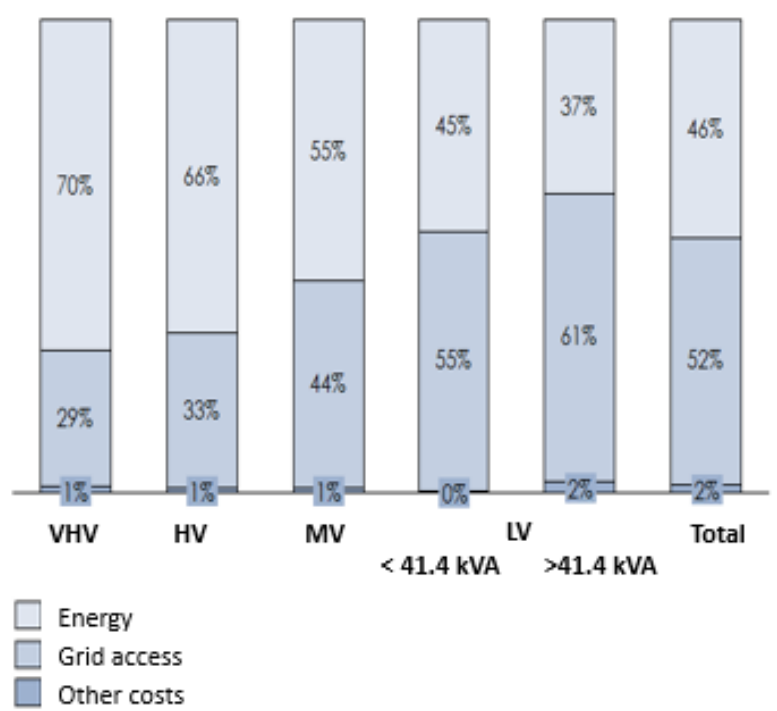

Figure 1 - Energy tariff cost structure in Portugal, excluding taxes (2015) [1] 
the grid and its quality of service, the optimization of sustainable drivers like energy efficiency, environmental

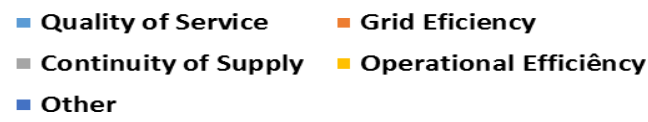

Figure 2 - Investment in Portuguese Grid 2015-17[2]

aspects and energy costs for clients or electrical sector costs, are classical drivers that cannot be discarded. Considering the distribution grid investment plan there are four main items that make up the investment: Continuity of Service, Technical Quality of Service, Grid Efficiency, and Operational Efficiency. As it shown in figure 2, the first two items sum up $60 \%$ of investment. Grid peak power is one of the key indicators that is strongly correlated with grid investment. Moreover, analyzing grid efficiency, and since technical losses are proportional to the square of current $\left(\mathrm{P}_{\text {losses }} \approx \mathrm{I}^{2}\right)$, the minimization of peak demand is a key factor to lower their value and strongly contributes to a more sustainable electrical system. Moreover, renewable energy sources (RES) integration is one of the DSO responsibilities according to European and Portuguese directives. Considering RES integration, Portugal is one of leading countries in Europe, according to national policies [3]. A quick overview on figure 3 clearly shows the strong growth of the renewable generation connected to the distribution grid ( $80 \%$ of overall Portuguese renewable capacity) which have been increasing year after year, even despite the Portuguese economic crisis the country is undergoing since 2010. This increase in RES connected to the distribution grid implies that the DSO faces new challenges since grids are beginning to be explored with a different strategy. They were deployed so that the power flowed from upstream to downstream, but they are now facing a new reality. One well known problem is the increase of

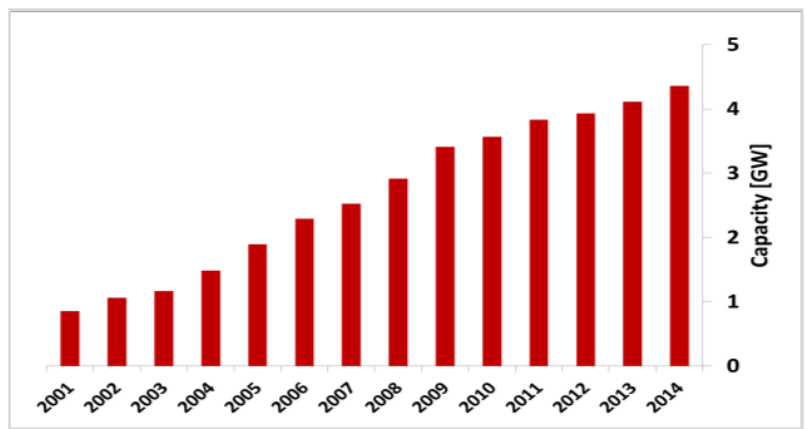

Figure 3 - Renewable Energy connected in distribution grid Portugal [3] voltage profiles, mainly in low short-circuit LV grids. Another considerable change is the clients' behaviour profiles that are getting a more active role than passive. New technologies and new energy management techniques are emerging. Since clients are not so aware of these techniques, innovative and real demonstrator projects like SENSIBLE should promote the first from clients to these new reality.

The aforementioned challenges and the demand for new energy services (like energy flexibility services) to distribution grids stakeholders, from retailers to customers or producers, can only be achieved within a smart grid concept. The key word to respond to a more volatile grid operation is flexibility, to be provided mainly to DSO.

The previous figures and facts outline three main conclusions of the Portuguese framework. i) the energy cost for LV costumer highly depends on two main items grid access costs and energy costs; ii) Quality-of-Service, Continuity of Supply and Grid efficiency are three of the main investment vectors, and this clearly shows its importance for the DSO mission; iii) Renewable generation integration is one of the DSO main challenges and responsibilities. This leads to new grid management techniques, where new use cases and tools developments should support new business models to be erected. This leads to four of the objectives of the use case studied in this paper, namely Continuity of Service, Quality of Service, Energy Efficiency and RES integration.

Figure 4 outlines a daily load diagram and energy market daily price where it can be shown that market energy price peak and peak power consumption are not completely coupled.

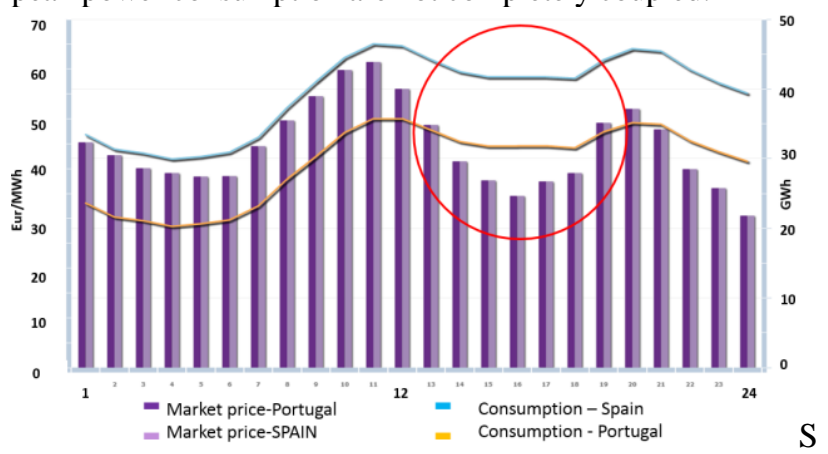

Figure 4 - Daily peak consumption and energy price in wholesale market [4]

Some often the energy price can be decreasing while the peak power still remains high. This reinforce the idea that energy and power must be managed integrated concerning the two main energy cost components, rather than separated. The last objective is to minimize energy costs paid by the client and it's considered that this must be done through an integrated management between grid access costs and energy cost price since they are not decoupled variables.

Taking into account the above framework, this paper to detail a use case where new energy services will be available to clients, which intends to reduce their energy costs (access and energy) through providing flexibility both to DSO and Retailer, as the following sections explain. 


\section{SENSIBLE USE CASE - FLEXIBILITY AND DSM IN THE MARKET PARTICIPATION}

The implementation of this use case is outlined in figure 4 where it is assumed that customer participation will occur through a Retailer or other Energy Service Company that acts in two timeframes (day-ahead and intraday) with complementary approaches, articulating regulated activities (grid management) and market activities (energy market). Grid access cost will be managed by a dynamic tariff applied by the DSO under regulated rules which shall represent an

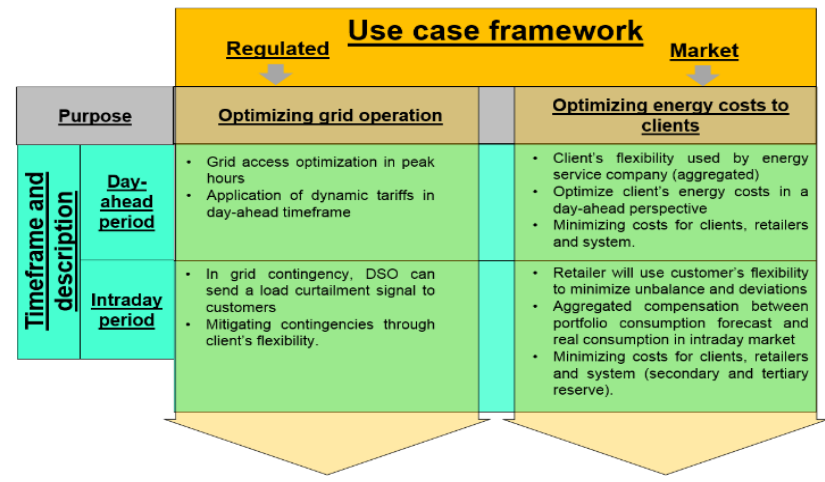

Figure 5- Use case framework

incentive for customers to adapt their peak consumption in case of technical constraints. This tariff should reward customers that contribute to grid management, rather than clients that lead to grid expansion costs. The tariff should also be related to the avoidable costs (i.e. in grid investment, operation and maintenance) by DSO when clients contribute with flexibility in benefit of the grid operation.

We can say that a dynamic tariff exists when they vary according to a certain purpose trying to incentive some type of behaviour. The aim of dynamic tariffs is to better reflect costs, either in terms of generation or distribution network. For the DSO, we can list some advantages dynamic tariff schemes can bring. First, they have some potential to lower the pace of growth of peak consumption. Networks are designed to accommodate maximum consumption. If peak consumption grows less, it means some investment can be deferred. Second, technical losses can decrease, if consumption has a flatter curve. Third, there will be a higher potential to integrate RES in the grid without compromising its reliability. Another important consequence has to do with the more efficient allocation of costs across customers, because dynamic schemes will tend to charge higher prices to the customers that actually cause the rise in the grid's peak consumption costs. Energy market benefits will come from market participation, where it's assumed that clients are equipped with flexibility management tools and flexible loads (as explained in Developments section) as well as that their flexibility will be used by an Energy Service Provider Company in an aggregated way.

\section{Day-ahead timeframe}

The client's final energy price combines the energy price resulting from wholesale market and the grid access regulated dynamic tariff. In case a technical constraint is foreseen, the dynamic tariff will charge more for grid's access, with the customer being warned in advance. If are forecasted such as excess of PV generation in a feeder, the DSO will apply a dynamic tariff to grid access cost item in order to promote energy consumption.

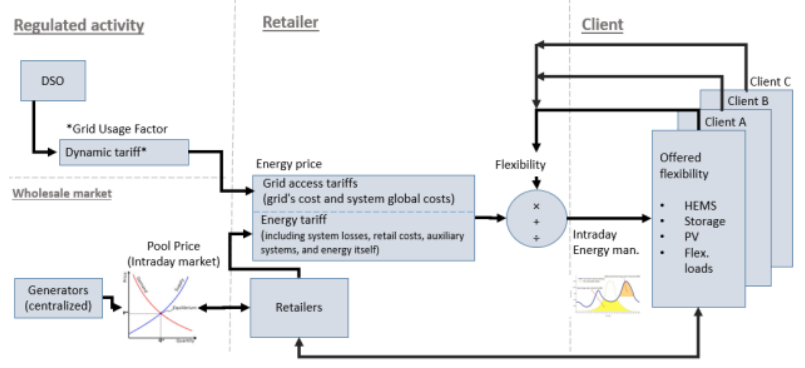

Figure 6 - Day-ahead use case outline

On the other hand an Energy Service Company (ESC) could optimize its market participation by managing the flexibility available in its clients' portfolio, optimizing the bids to the market and offers to the customers. This is done considering both the day-ahead wholesale electricity market and the optimal participation in the intraday market.

\section{Intraday timeframe}

In the intraday timeframe, considering a BaU scenario, any unbalance between day-ahead offers and intraday real consumption would be compensated in intraday market with higher costs to retailers that fails their previous offers and predictions. Moreover any deviations would be compensated by the TSO in secondary reserve market and this associated

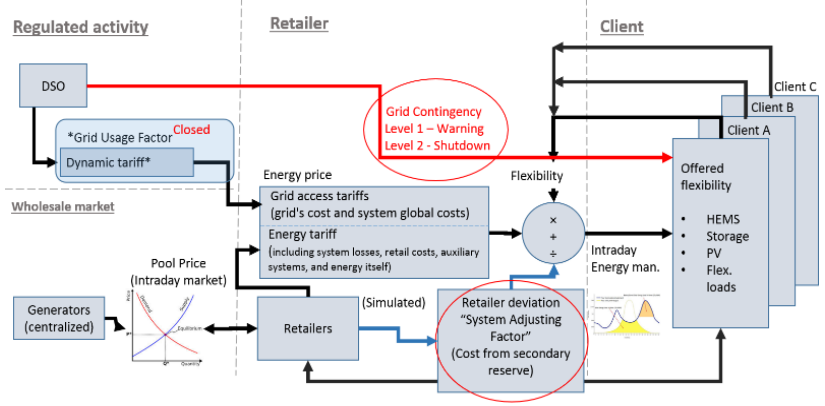

Figure 7 - Intraday use case outline

cost (System Adjusting Factor) would be paid by retailers whose clients failed their load prediction.

These costs could be minimized using better predictions of the consumption and the flexibility of each within a retailer's client portfolio of clients in wide flexible market participation. This will result in a cost reduction to the retailers and these benefits will be shared also with customers 
according a contractual relationship.

Considering regulated activity, in the intraday timeframe the dynamic grid access tariff will not change due to strict regulated rules and grid access limitations will only be allowed under severe technical constraints. In such case client's load curtailment will be requested by DSO through a Demand Side Management (DSM) signal to each client's smart meter and simultaneously to the Retailer which will take advantage of its Energy Market Service Platform (ESMP) to optimize their clients load profile, through the HEMS according to grid limitation, as will be explained afterwards. A quick example of application is here described: a LV grid, because of any technical reason is forced to reduce its peak power to avoid a grid blackout. This amount of power should be reduced by this grid's clients according to fair and regulated rules, so that Continuity of Service can be assured. Under this technical constraint, those clients who could adapt their consumption would be disconnected by a DSM signal, while the technical constraint is active. These would be a clear situation where customers are invited to participate in grid management collecting benefits of the smartgrid infrastructure contributing to a more efficient grid.

\section{DEMONSTRATION AND ARCHITECTURE}

SENSIBLE' Évora demonstrator will be located in Valverde, a small village in Évora district, where 40 of $238 \mathrm{LV}$ consumers are equipped with a Home Energy Management System (HEMS), which will manage Residential Energy Storage System, PV System, and Flexible Loads like Electrical Water Heaters (WH) among others, as outline in figure 8 . The HEMS will be managed by high level tools. The HEMS will have two drivers both from market where market contribution will be calculated (EMSP) and from regulated activity where grid access costs will be managed (Grid Service Platform).

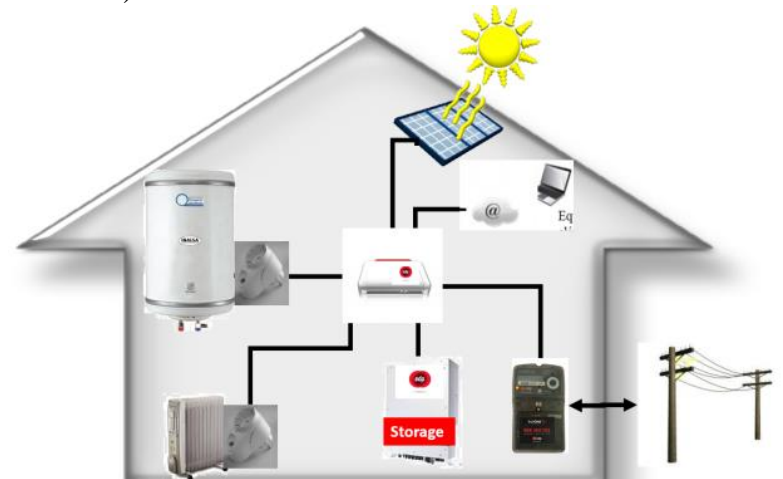

Figure 8 - Residential energy management equipment in SENSIBLE's Évora demonstrator

This HEMS will be managed through an ICT (information and communications technologies) architecture where two main routes interact to the client: i) market route (red) for market based services and ii) regulated route (green) for DSO application services to grid management. The elements depicted in blue are the ones that contribute to the implementation of the Use Case of Flexibility and DMS in market participation

The EMSP will receive the inputs of the flexibility boundaries from each customer (i.e. at which time WH can be switch on or off, at what time batteries could be full charged, at what time flexible loads can be switch off) so that this constraints can be considered in load profiles' optimization. Several independent actors will take important role in this use case. A Residential Flexibility Aggregator tool will be able to compile clients' flexibility inputs and properly divide the results of market participation.

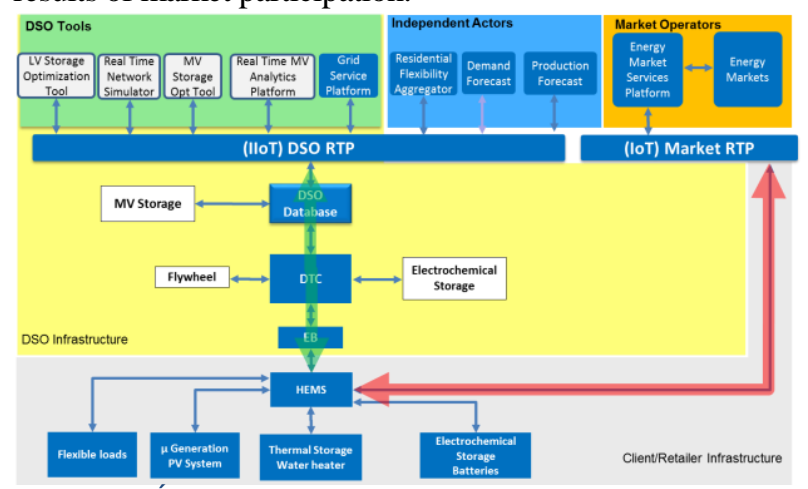

Figure 9 - Évora demonstrator architecture.

A Demand Forecast tool and Production forecast tool will forecast generation and load profiles as an input to both grid access costs and available flexibility from customer's estimation. Afterwards, the EMSP will calculate the market and regulated items and optimize the best aggregated load profiles according to available flexibility from customers. The result of this aggregated flexibility, as a result of market participation and DSO requirements, will be breakdown through set points to HEMS among individual households according to the customers' flexibility usage.

\section{CONCLUSIONS AND FUTURE WORK}

The Use Case of flexibility and DSM in market participation developed under the scope of SENSIBLE project aims to bring benefits to customers and to the grid. It will be test in a real environment, including $16 \%$ of Évora demonstrator LV customers. The use case results and conclusions are to be shared in next steps. Moreover, the regulatory framework will be tested so that new technics and business models can be ratified and true value materialized.

\section{REFERENCES}

[1] - EDP Distribuição

[2] - Plano de Desenvolvimento e Investimento da Rede de Distribuição - www.erse.pt

[3] - Diário da República, 1. ${ }^{a}$ série - N. ${ }^{\text {o }} 70$

[4] - www.mibel.com 